\begin{tabular}{|l|l|l|l|l|l|l|}
\hline InterteXto & Uberaba & UFTM & $\begin{array}{l}\text { v. 3 } \\
\text { n. 1 }\end{array}$ & p. 91-108 & 2010- jan. / jun. & ISSN 1981-0601 \\
\hline
\end{tabular}

\title{
GÊNEROS TEXTUAIS NO ENSINO DE LEITURA EM LE: NA TEORIA, EM GERAL
}

\author{
TEXTUAL GENRE IN TEACHING L2 READING: MOSTLY IN THEORY
}

\begin{abstract}
Alessandra Baldo ${ }^{1}$
Resumo: Desde a publicação dos $\mathrm{PCNs}$ há mais de uma década, abordagens sociointeracionistas de ensino-aprendizagem de língua materna e estrangeira, com a indissociável ênfase na concepção de ensino via gêneros textuais, têm recebido cada vez mais destaque, como atestam o crescente número de publicações e de eventos organizados a partir dessas propostas. Ainda que alguns estudos já tenham mostrado o descompasso entre os parâmetros elaborados pelo Ministério da Educação e a prática de sala de aula de professores (Bonini, 2001; Biasi-Rodrigues, 2002; Antunes, 2002; Baldo, 2005; Silva, 2007), pouco tem sido dito sobre o graduando em Licenciatura em Letras. Este artigo representa uma tentativa de contribuir nesse sentido, ao buscar avaliar em que medida este licenciando utiliza o conhecimento teórico-metodológico adquirido ao longo de seu curso nas disciplinas de estágio, momento em que a preparação de materiais didáticos é realizada com vistas à prática docente. Essa avaliação é realizada a partir de quatro amostras de atividades elaboradas por alunos matriculados na disciplina de Estágio de Língua Inglesa Ensino Médio no ano de 2010, sob minha supervisão. A dificuldade de transposição didática verificada nessas atividades reflete uma situação comum também a outros graduandos, e teve como consequência uma reflexão sobre essa realidade, apresentada ao longo deste trabalho.
\end{abstract}

Palavras-chave: ensino-aprendizagem de língua estrangeira; gêneros textuais; abordagens sociointeracionistas.

Abstract: Since PCNs have been published, more than a decade ago, sociointeractive approaches to L1 and L2 teaching and the inseparable notion of language teaching through textual genres have been strongly emphasized, as the growing number of publications and academic events organized around both themes, PCNs and socio-interactionism, can easily testify. Even though some studies have already shown that the guidelines set by the Brazilian Ministry of Education do not square with the teaching practices of a number of teachers (Bonini, 2001; Biasi-Rodrigues, 2002; Antunes, 2002; Baldo, 2005; Silva, 2007), little has been said about the studentteacher. Within this context, this articles attempts to offer a contribution by assessing to what extent this teacher-to-be uses the theoretical knowledge acquired throughout the under-graduation course in the Teacher Training, a time when the elaboration of didactic materials is followed by a teaching practice period. The assessment was based on four reading activities planned by Language under-graduate students (Portuguese and English) enrolled in the English Teacher Training in the year 2010.

\footnotetext{
${ }^{1}$ Professora adjunta da Faculdade de Letras - Departamento de Línguas Estrangeiras da Universidade Federal de Pelotas, RS. lelabaldo@terra.com.br
} 


\begin{tabular}{|l|l|l|l|l|l|l|}
\hline InterteXto & Uberaba & UFTM & $\begin{array}{l}\text { v. 3 } \\
\text { n. } 1\end{array}$ & p. 91-108 & 2010 - jan. / jun. & ISSN 1981-0601 \\
\hline
\end{tabular}

The obstacles students presented to apply the theoretical concepts to their didactic materials reflected a common situation to other under-graduate students, a fact that has led to a reflection of the problem.

Key-words: foreign language learning and teaching; textual genres; socio-interactive approaches.

\section{Introdução}

Propostas de ensino de língua - tanto materna (L1) como estrangeira (2) - fundamentadas em uma concepção sociointeracionista da linguagem, com a indissociável valorização do conceito de gênero textual e/ou discursivo, têm sido amplamente divulgadas e discutidas no ambiente acadêmico e pelas instituições governamentais responsáveis pelas diretrizes relativas à educação linguística há mais de uma década, se adotarmos como data de referência a publicação dos Parâmetros Curriculares Nacionais - PCNS em 1998.

Naturalmente que os PCNs, ao argumentarem a favor do sociointeracionismo e da noção bakhtiniana de gênero para o ensino de língua, não foram os precursores de tais propostas. Elas já haviam sido sugeridas anteriormente por vários estudiosos da linguagem, como, por exemplo, Orlandi (1988), Geraldi (1991) e Moita Lopes (1996), para citar apenas três nomes de referência. ${ }^{2}$ Entretanto, é inegável a contribuição que os PCNs ofereceram, devido especialmente a seu status de documento oficial, ao agruparem em um só texto os estudos anteriores de diversos autores e pesquisadores da área de ensino-aprendizagem de línguas e, tão importante quanto, ao chamarem a atenção e sugerirem meios para a transposição didática dos parâmetros sugeridos para os currículos das aulas de línguas.

Essas contribuições dos PCNs refletiram imediatamente nas propostas pedagógicas dos cursos de Licenciatura em Letras, como seria inevitável. Desde a sua publicação até cada nova complementação ao primeiro

${ }^{2}$ Orlandi, "E. P. Leitura: questão linguística, pedagógica ou social", in Leitura e discurso, 1988, p. 35-40 ; Geraldi, W. J. Portos de Passagem, 1991; Moita Lopes, L. P. "Um modelo interacional de leitura", in Oficina de Linguística Aplicada, 1996, p 139-143. Ainda que nem sempre as expressões sociointeracionismo e gêneros textuais estejam explícitas nos trabalhos desses autores, é possível perceber uma concepção de ensino de língua que apregoa princípios bastante semelhantes aos dos PCNs. 


\begin{tabular}{|l|l|l|l|l|l|l|}
\hline InterteXto & Uberaba & UFTM & $\begin{array}{l}\text { v. 3 } \\
\text { n. } 1\end{array}$ & p. 91-108 & 2010 - jan. / jun. & ISSN 1981-0601 \\
\hline
\end{tabular}

documento de 1998, os currículos dos cursos de Letras foram adaptados a fim de reservar momentos específicos para, primeiramente, analisar as novas diretrizes, como também, em seguida, transformar essas diretrizes em atividades e materiais didáticos. Desse modo, pareceria simples confirmar a hipótese de que professores de língua em formação já tivessem incorporado os parâmetros apregoados pelos PCNs em suas práticas docentes.

Não tem, contudo, sido simples assim - pelo menos no que diz respeito à grande parte dos alunos que tenho orientado nas disciplinas de Estágio III e IV de Língua Inglesa do curso de Licenciatura em Letras. Ainda que, a princípio, a base teórica que Ihes é oferecida ao longo do curso deveria ser suficiente para possibilitar a objetivada transposição didática, isso de fato não tem, de modo geral, ocorrido.

Tendo esse contexto como pano de fundo, esse artigo tem como objetivo ilustrar a dificuldade de licenciandos em Letras de transformar em práticas de sala de aula as teorias de ensino-aprendizagem de língua estudadas ao longo do curso, a partir de amostras de propostas de planos de aula elaborados para a disciplina de Estágio de Língua Inglesa - ensino médio. Esperamos, com isso, motivar uma reflexão, tanto por parte dos alunos de Letras como por parte dos professores responsáveis pela formação desses alunos, a respeito das práticas docentes concebidas por licenciados nos semestres finais do curso.

$\mathrm{O}$ artigo está organizado em quatro partes. Na primeira, descrevemos a justificativa dos PCNs de língua estrangeira para a adoção da abordagem sociointeracionista, e, daí, para o ensino da língua via gêneros textuais. Na segunda, outras razões destacadas por estudiosos da área para a relevância do ensino-aprendizagem de língua - tanto materna como estrangeira - via gêneros também serão mostradas. Na terceira parte, serão apresentados exemplos de atividades elaboradas por alunos do curso de Licenciatura em Letras matriculados na disciplina de Estágio de Língua Inglesa, a fim de mostrar o descompasso entre a concepção subjacente de ensino de língua 


\begin{tabular}{|l|l|l|l|l|l|l|}
\hline InterteXto & Uberaba & UFTM & $\begin{array}{l}\text { v. 3 } \\
\text { n. } 1\end{array}$ & p. 91-108 & 2010 - jan. / jun. & ISSN 1981-0601 \\
\hline
\end{tabular}

apresentada por estas e a concepção preconizada pelos PCNs. A última parte será dedicada às considerações finais, elaboradas com base nas análises dos materiais didáticos apresentados e nas diretrizes recentes para o ensinoaprendizagem de línguas estrangeira.

\section{Sociointeracionismo e Gêneros Textuais nos PCNs}

Nos PCNs para o ensino fundamental de língua estrangeira, a valorização da abordagem sociointeracionista é evidenciada ao longo do documento. Já no início da descrição das diretrizes, é chamada a atenção para o fato de a possibilidade de se "usar a aprendizagem de línguas como espaço para se compreender, na escola, as várias maneiras de se viver a experiência humana" (1998, p. 24-25) estar atrelada a duas questões teóricas de base: a natureza da linguagem é sociointeracional; o processo de aprendizagem é de cunho sociointeracional. Essas premissas são seguidas por uma definição do significado que esses termos possuem no documento:

O uso da linguagem [...] é essencialmente determinado pela sua natureza interacional[...] As pessoas se envolvem em interações escritas e orais para agirem no mundo social em um determinado momento, em relação a quem se dirigem ou a quem se dirige a elas. (1998, p. 27)

Com relação aos PCNS de língua estrangeira para o ensino médio, pode-se dizer que muito pouco é apresentado no que diz às concepções de linguagem a serem tomadas como fundamento para o ensino-aprendizagem. De qualquer modo, isso não chega a parecer problemático, já que se espera serem as mesmas sugeridas para o ensino fundamental, partindo-se do princípio de se tratar de um documento coerente. Nesse sentido, ao enfatizarem o papel da comunicação como meta primeira no ensino de línguas estrangeiras no ensino médio, dado seu papel "imprescindível no mundo moderno, com vistas à formação profissional, acadêmica ou pessoal" (1999, p.31), é possível inferir a presença do sociointeracionismo na linguagem, 


\begin{tabular}{|l|l|l|l|l|l|l|}
\hline InterteXto & Uberaba & UFTM & $\begin{array}{l}\text { v. 3 } \\
\text { n. } 1\end{array}$ & p. 91-108 & 2010 - jan. / jun. & ISSN 1981-0601 \\
\hline
\end{tabular}

especialmente a partir da ênfase na comunicação bem-sucedida, nas suas mais diversas manifestações.

Já no que diz respeito especificamente ao emprego de gêneros textuais nas disciplinas de língua estrangeira, nada é encontrado. Acreditamos que isso aconteça por duas razões: primeiro, porque ao (re)afirmarem a proposta sociointeracionista para o ensino da língua, também estão (re)afirmando a proposta de ensino de língua via gêneros, já que são conceitos indissociáveis; segundo, porque a noção de gênero é bastante enfatizada nos PCNs para o ensino-aprendizagem de língua materna, e parece razoável supor que a mesma escolha teórico-metodológica tenha sido adotada para o ensinoaprendizagem de língua estrangeira. Cabe lembrar, nesse contexto, que a definição de gêneros aparece já no início dos PCNs de língua materna para os $1^{\circ}$ e $2^{\circ}$ ciclos, logo após a caracterização de termos-chave como língua, discurso e textos, definidos como "resultados da atividades discursivas que se organizam dentro de um determinado gênero". (PCNs Língua Materna - Ensino Fundamental - $1^{\circ}$ e $2^{\circ}$ ciclos, p. 26) A noção de gênero apresentada é sintetizada da teoria dialógica de Bakhtin do seguinte modo: "os vários gêneros existentes, por sua vez, constituem formas relativamente estáveis de enunciados, disponíveis na cultura, caracterizados por três elementos: conteúdo temático, estilo e construção composicional." 3 (p. 26)

\section{Sociointeracionismo e Gêneros Textuais no Ensino de Língua}

As justificativas apresentadas pelos PCNs para o emprego da noção de gêneros no ensino de língua têm sido bem aceitas por diversos estudiosos da linguagem. Meurer (2000), por exemplo, argumenta que uma das razões para o estudo do gênero está no fato de ele se constituir em uma opção mais atraente

\footnotetext{
${ }^{3}$ A definição dos três elementos constituintes do gênero é reservada para os PCNs de língua materna para os ciclos 3 e 4: o conteúdo temático é definido como "o que é ou pode tornar-se dizível por meio do gênero", a estrutura composicional, como a "estrutura particular dos textos pertencentes ao gênero", o estilo, como "configurações específicas das unidades de linguagem, derivadas, sobretudo, da posição enunciativa do locutor, conjuntos particulares de sequências que compõem o texto, etc.". (p. 21)
} 


\begin{tabular}{|l|l|l|l|l|l|l|}
\hline InterteXto & Uberaba & UFTM & $\begin{array}{l}\text { v. 3 } \\
\text { n. } 1\end{array}$ & p. 91-108 & 2010 - jan. / jun. & ISSN 1981-0601 \\
\hline
\end{tabular}

do que o ensino da linguagem humana fundamentada na gramática, coesão, modalidades retóricas e coerência na medida em que "responderia de maneira mais adequada a questões relativas aos diferentes usos da linguagem e na interface com o exercício da cidadania" (p.152). Segundo o autor, a ineficiência da abordagem tradicional deve-se exatamente ao fato de não se preocupar e não dar conta das "situações específicas em que os indivíduos efetivamente utilizam a linguagem como instrumento de interação, reprodução e/ou alteração social".

Ele acrescenta ainda que tanto o ensino como a pesquisa baseadas no estudo de gêneros textuais são importantes porque, em primeiro lugar, não nos comunicamos através de modalidades retóricas nem de textos em geral, mas de gêneros textuais específicos. Além disso, como a própria cultura de um país é caracterizada pelo conjunto de gêneros textuais de seus cidadãos, a investigação e o ensino destes são essenciais para a formação de profissionais responsáveis pelo ensino da linguagem no país. ${ }^{4}$

Com relação à concepção de ensino de leitura em língua estrangeira, Dourado (2008) conclui que os PCNs apresentam uma conjunção entre a perspectiva interacionista e o componente social, especialmente a partir da verificação de que o documento equipara a habilidade de leitura com a capacidade de (i) situar o texto, (ii) identificar o autor, (iii) os possíveis leitores e (iv) os propósitos comunicativos. Para a autora, é essa abordagem de ensino que deve ser adotada se o objetivo é desenvolver a capacidade de o aluno produzir sentido para textos de gêneros diversos que circulam na sociedade, aprimorando, assim, sua capacidade de análise e reflexão.

4 Importante aqui relembrar as três possíveis abordagens da escrita e da palavra na escola sistematizadas por Schnewly e Dolz (1999) - a comunicação é quase inexistente e o gênero torna-se pura forma linguística cujo objetivo é seu domínio; a escola é tomada como lugar autêntico de comunicação, de produção e de compreensão de textos (e, daí, de gêneros); os gêneros são levados para a escola exatamente como funcionam nas práticas de linguagem de referência, e o ensino visaria ao domínio de instrumentos necessários para funcionar nessas práticas - e buscar, a partir da perspectiva de Meurer, um equilíbrio entre as duas últimas no ambiente escolar. 


\begin{tabular}{|l|l|l|l|l|l|l|}
\hline InterteXto & Uberaba & UFTM & $\begin{array}{l}\text { v. 3 } \\
\text { n. } 1\end{array}$ & p. 91-108 & 2010 - jan. / jun. & ISSN 1981-0601 \\
\hline
\end{tabular}

De modo semelhante, Silva (2007) argumenta a favor do encontro entre conceitos-chaves de Bakhtin (1953/1997) e a hipótese de trabalho de Bronckart (2003) e Schneuwly e Dolz (2004) - ou seja, o gênero constitui-se em instrumento de mediação entre práticas sociais e objetos escolares - a fim de desenvolver uma metodologia significativa de ensino de língua estrangeira. Após observar aulas de leitura em língua inglesa de uma turma de $8^{\mathrm{a}}$ série de ensino fundamental de uma escola pública de Minas Gerais entre maio a dezembro de 2003, a autora concluiu que, embora os alunos tenham tido contato com vários gêneros, os aspectos mais valorizados foram os conteúdos dos textos e a apropriação das características formais, tendo a dimensão sóciocultural sido reservada para um segundo plano: "a questão dos propósitos comunicativos, das finalidades e usos sociais dos gêneros não foi propriamente objeto de reflexão". (p. 10) Para a autora, essa abordagem interferiu no processo de compreensão dos alunos, o que provavelmente não teria ocorrido se a noção de gênero fosse explorada em todo seu potencial.

\section{Análise de Propostas de Atividades Didáticas para Aulas de Língua Estrangeira}

A despeito de todas as vantagens que o ensino-aprendizagem de língua por um viés sociointeracionista que contemple a noção de gênero promete oferecer, nessa seção buscaremos mostrar que a adoção dessa concepção teórico-metodológica não é verificada, por vezes, nem mesmo em licenciados em Letras nos estágios finais de seu curso de graduação, momento em que, a princípio, a integração entre teoria e prática deveria estar em maior evidência.

Os exemplos utilizados foram selecionados de uma proposta de elaboração de uma aula de leitura cujo tópico fosse turismo, solicitada aos estudantes da disciplina de Estágio III no primeiro semestre de 2010, quando esteve sob minha responsabilidade. A atividade foi proposta com base na leitura e discussão prévia do texto "Dez anos de PCNs de língua estrangeira sem avaliação dos livros didáticos pelo PNLD", de Dourado (2008). Nesse 


\begin{tabular}{|l|l|l|l|l|l|l|}
\hline InterteXto & Uberaba & UFTM & $\begin{array}{l}\text { v. 3 } \\
\text { n. } 1\end{array}$ & p. 91-108 & 2010 - jan. / jun. & ISSN 1981-0601 \\
\hline
\end{tabular}

texto, a autora analisa duas atividades baseadas em textos de dois livros didáticos de inglês adotados em escolas da rede pública com o objetivo de verificar se essas exploravam os gêneros textuais apresentados ou se apenas utilizavam os textos como instrumentos para apresentarem o novo vocabulário e novas estruturas gramaticais. Para tanto, Dourado primeiramente retoma os PCNs para o ensino de língua estrangeira, enfatizando a necessidade do estudo dos gêneros textuais, e em seguida analisa as atividades didáticas. Assim, a leitura desse texto antes da solicitação da elaboração da atividade didática foi importante na medida que possibilitou aos alunos relembrarem a perspectiva sociointeracionista e a noção de gênero textual, retomando, assim, noções teóricas chaves para o ensino de língua estrangeira.

Devido a restrições de espaço, foram delimitados quatro exemplos, todos utilizados com permissão dos autores. Por fim, cabe notar que esse plano de aula foi o primeiro que os alunos elaboraram para a disciplina, após cinco encontros dedicados a leituras sobre os PCNs de línguas estrangeiras, mais especificamente com relação à abordagem de leitura e de gêneros textuais.

\section{Proposta 1}

Iniciemos pelo exemplo mais curto, mas nem por isso menos ilustrativo. O plano de aula desses alunos tinha como base a versão em inglês de uma página da internet de um resort situado em uma praia do nordeste brasileiro, na qual aparecia, como texto principal, uma descrição de dois parágrafos do resort. Entre os conteúdos estabelecidos para a aula, foram listados (i) compreensão de texto e (ii) vocabulário - turismo, nada sendo mencionado sobre gêneros textuais. Já no item seguinte, objetivos, foram listados dois:

- Identificar o vocabulário apresentado no texto e em outros materiais que virão em aulas posteriores. 


\begin{tabular}{|l|l|l|l|l|l|l|}
\hline InterteXto & Uberaba & UFTM & $\begin{array}{l}\text { v. 3 } \\
\text { n. } 1\end{array}$ & p. 91-108 & 2010 - jan. / jun. & ISSN 1981-0601 \\
\hline
\end{tabular}

- Reconhecer o gênero textual site de internet e suas funções material de propaganda. (2010, material não-publicado, itálico nosso).

Em primeiro lugar, chama a atenção o fato de o trabalho com gêneros fazer parte dos objetivos da aula elaborada, mas não dos conteúdos. Além disso, referir-se ao material de propaganda como uma das funções do gênero textual site de internet é problemático, já que a propaganda é um gênero nela mesmo, e a página da internet funciona, nesse caso, como o suporte dessa propaganda. Observando-se esses dois problemas teórico-metodológicos já em dois aspectos fundamentais de qualquer proposta de atividade didática - ou seja, os conteúdos previstos e os objetivos a serem alcançados - as chances de esse plano ser bem-sucedido, caso transformado em prática docente, estariam comprometidas, pelo menos no que diz respeito à apropriação do gênero pelos alunos.

\section{Proposta 2}

A proposta desse plano é baseada no texto "The Brazilian Phantasy Place", retirada de uma página da internet sobre turismo. O texto é uma descrição da ilha Fernando de Noronha, com dezoito linhas e sem divisão em parágrafos. Os alunos recebem o texto com cinco lacunas, as quais devem ser completadas com o nome da ilha, e essa constitui uma das tarefas de compreensão. Em uma parte do plano, a aluna explicita que "as atividades trabalham a habilidade de leitura com o objetivo de ampliar o uso e contato dos alunos com as diferentes formas textuais em língua inglesa, nesse caso um texto do gênero propaganda" (2010, material não publicado). A título de ilustração, a parte inicial do texto é apresentada a seguir.

The Brazilian Phantasy Place

Distance kept this small island protected for centuries. is $340 \mathrm{Km}$ off the Brazilian coast, and the Access to and permanence in the island is strictly controlled, to prevent damages to the environment; the beaches are as beautiful as 


\begin{tabular}{|l|l|l|l|l|l|l|}
\hline InterteXto & Uberaba & UFTM & $\begin{array}{l}\text { v. 3 } \\
\text { n. } 1\end{array}$ & p. 91-108 & 2010 - jan. / jun. & ISSN 1981-0601 \\
\hline
\end{tabular}

they were 500 years ago. Mean annual temperature is 26 degrees Celsius, and winds are relieving and permanent. brazil.com/tourism/FDN.html) was officially found in... (www.v-

O primeiro aspecto da proposta que vai de encontro a uma abordagem sociointeracionista de ensino de língua estrangeira via gêneros é a desconfiguração do ambiente e do formato em que o texto se encontrava originalmente. Em uma análise de textos utilizados em livros didáticos de inglês, Dourado (2008) também testemunhou essa descaracterização do gênero textual, argumentando que, com isso, é perdida a oportunidade de "inserir o aluno-leitor em vivências de aprendizagem formativas que poderiam Ihe permitir familiarizar-se com esse gênero e dele tornar-se leitor" (p. 7) No caso específico da proposta de atividade apresentada aqui, e com base no objetivo declarado do estagiário de ampliar o uso e contato dos alunos com as diferentes formas textuais em língua inglesa, nos deparamos aqui com uma evidente contradição teórico-metodológica: se a intenção é ampliar o contato e uso de diferentes gêneros em língua inglesa pelos alunos, o primeiro cuidado a tomar é selecionar textos autênticos sempre que possível. ${ }^{5}$

Deixando o aspecto da descaracterização do gênero e focalizando nas atividades elaboradas pelo aluno para explorar esse texto, encontramos novamente uma dissonância entre o que é teorizado no plano de aula e o que é de fato elaborado para relacionar teoria e prática. Há quatro exercícios propostos, mas em nenhum deles é possível perceber uma tentativa de familiarizar os alunos com o gênero proposto. A primeira atividade se resume em solicitar aos alunos que sublinhem tanto as palavras cognatas como as palavras que já são conhecidas, ainda que não cognatas. $\mathrm{Na}$ segunda

\footnotetext{
${ }^{5}$ Em determinados contextos de ensino-aprendizagem, a possibilidade de utilizar somente textos autênticos não é possível, e aí pensamos que cabe ao professor avaliar se o benefício de retirar o texto de seu ambiente original - ou seja, possibilitar ao aluno entrar em contato com esse gênero, ainda que não de maneira ideal - é maior do que o dano - nesse caso, adquirir uma noção equivocada do funcionamento desse gênero na sociedade. De qualquer modo, quando a opção for por uma mudança de contexto, é importante atentar para que as alterações se mantenham no menor número possível.
} 


\begin{tabular}{|l|l|l|l|l|l|l|}
\hline InterteXto & Uberaba & UFTM & $\begin{array}{l}\text { v. 3 } \\
\text { n. } 1\end{array}$ & p. 91-108 & 2010 - jan. / jun. & ISSN 1981-0601 \\
\hline
\end{tabular}

atividade, já mencionada anteriormente, o aluno é convidado a identificar o lugar que é descrito no texto, completando as lacunas. Além disso, deve buscar uma parte específica do texto que comprove a sua escolha. A terceira atividade consiste em buscar no texto os equivalentes em inglês de uma série de expressões traduzidas para o português, como "fortemente controlada", "preservar danos", "temperatura média anual" e "isolamento do lugar". Finalmente, na quarta atividade o aluno deve assinalar a palavra/expressão que não corresponde ao grupo, sendo essas as opções: a) officially - wealthy - completely; b) occupied - reclaimed - kept; c) centuries - access - tourists.

Não é necessário despender muito tempo para categorizar as atividades um e três como sendo de checagem e ensino de vocabulário, e a atividade quatro como sendo de identificação de estruturas gramaticais da língua inglesa (letra $a$, sufixo formador de advérbio; letra $b$, formas verbais regulares $e$ irregulares do passado; letra c, distinção entre verbos e substantivos). Assim, o único exercício que de fato tem como foco a compreensão do texto é o de número 2, que solicita o preenchimento das lacunas com o nome do local descrito, de acordo com os dados disponíveis no texto. Como vimos anteriormente, ainda que tal atividade tenha seu valor no processo de ensinoaprendizagem de língua estrangeira, do mesmo modo que todas as outras três elaboradas pelo aluno, ela não se sustenta quando uma das preocupações mencionadas na elaboração do plano de aula é a de proporcionar o contato e uso de diferentes gêneros na língua inglesa por parte dos alunos, como nesse caso.

\section{Proposta 3}

Essa proposta de aula de leitura teve como tema principal a Copa do Mundo 2010, fato que estava em evidência na época devido à proximidade com a abertura do evento. O texto selecionado foi retirado da internet e consistia em uma descrição do estádio Ellis Park, em Johanesburgo, o qual sediaria o primeiro jogo do Brasil na Copa, em 15 de junho. Após uma gravura 


\begin{tabular}{|l|l|l|l|l|l|l|}
\hline InterteXto & Uberaba & UFTM & $\begin{array}{l}\text { v. 3 } \\
\text { n. } 1\end{array}$ & p. 91-108 & 2010 - jan. / jun. & ISSN 1981-0601 \\
\hline
\end{tabular}

do estádio, havia informações relacionadas à história, localização e estrutura física atual do estádio. O texto seguia com um mapa localizando a cidade sulafricana e o estádio, como também outros estádios que sediariam os jogos da Copa. Por fim, aparecia uma tabela com a informação sobre os jogos, com a data, horário, grupo e nome da seleção.

Ainda que não tenha sido estabelecida qualquer relação entre o gênero textual escolhido e seu papel de facilitador no processo de compreensão no plano de ensino do estagiário ${ }^{6}$, é possível perceber essa preocupação, ainda que subliminarmente, nas três primeiras questões que compunham a atividade de leitura elaborada para os alunos. As questões são descritas a seguir.

1 Que tipo de texto é este?

2 Quais os tipos de texto que aparecem?

3 Qual a sua finalidade?

O primeiro aspecto que chama atenção, ao observá-las, é a já bastante comentada, e ainda persistente, tendência a tratar gênero e tipo textual como sinônimos, a despeito de suas naturezas bastante diversas. Nesse sentido, cabe salientar aqui que, da mesma forma que entendemos que a valorização do ensino de língua/leitura via gêneros no ensino fundamental/médio não se dá necessariamente por meio de questões como "a que gênero pertence esse texto?", também entendemos que questões que focalizem os aspectos tipológicos do texto, ao invés dos aspectos funcionais, prestam um desserviço ao desejado entendimento do texto, pelo aluno, como evidência material das relações sociointeracionais que acontecem pela linguagem através dos diferentes gêneros. ${ }^{7}$ Nesse sentido, a questão 1 não se justifica como pergunta

\footnotetext{
${ }^{6}$ Os objetivos específicos da aula consistiam em: (1) trazer para o aluno notícias sobre a Copa do Mundo de 2010, na África do Sul; (2) desenvolver a compreensão de pontos [gramaticais] específicos a serem questionados na próxima seção deste plano; (3) trabalhar a estrutura passiva da língua inglesa, sua função comunicativa e gramatical; (4) incentivar o interesse dos alunos por este campeonato, através de atividades realizadas em aula.

7 Dada a diversidade de gêneros atuais e os novos gêneros criados a partir da mídia virtual, a classificação de alguns deles é uma tarefa bastante complexa. Assim, de acordo com
} 


\begin{tabular}{|l|l|l|l|l|l|l|}
\hline InterteXto & Uberaba & UFTM & $\begin{array}{l}\text { v. 3 } \\
\text { n. } 1\end{array}$ & p. 91-108 & 2010 - jan. / jun. & ISSN 1981-0601 \\
\hline
\end{tabular}

inicial, pois impossibilita pensar o texto como algo real com uma função definida.

Um segundo aspecto que cabe observar diz respeito às duas primeiras questões - "Que tipo de texto é este?" e "Quais os tipos de texto que aparecem?". Lembrando a descrição do texto utilizado feita anteriormente, é possível caracterizá-lo como essencialmente descritivo em seu aspecto tipológico, e pertencente ao gênero propaganda, se analisado em seu ambiente discursivo mais amplo: o texto se encontra em uma página do ícone "estádios" do site da FIFA criado para a Copa do Mundo 2010, o qual apresenta várias informações, desde dados sobre cidades e estádios que sediariam o evento, passando por hotéis disponíveis para reservas on-line até compra de pacotes para a Copa, com o objetivo primeiro de atrair público para o evento. Como também já descrito, o texto apresenta informação verbal e não-verbal, com uma ilustração do estádio e com um mapa da África situando os estádios em que ocorreriam os jogos da Copa.

Isso considerado, a segunda questão evidencia dois problemas. O primeiro é o da provável confusão que causaria entre os alunos frente à solicitação sobre os tipos de textos, já que há apenas um texto de tipologia exclusivamente descritiva, ilustrado com gravuras e tabelas. $O$ segundo, e ainda mais grave, é o relativo à dificuldade de o classificarem em termos de sua função comunicativa sem disporem do ambiente discursivo mais amplo, ou seja, o site da FIFA. É exatamente essa falta de contexto que representaria um obstáculo à resposta à questão de número três, na qual a finalidade do texto apresentado é solicitada.

\section{Proposta 4}

A última proposta de atividade de leitura selecionada para ilustrar casos

Marcuschi (2008), entendemos que a categorização dos gêneros por si não deve ser uma preocupação dos estudiosos, mas sim a explicação de "como eles se constituem e circulam socialmente". (p. 159) 


\begin{tabular}{|l|l|l|l|l|l|l|}
\hline InterteXto & Uberaba & UFTM & $\begin{array}{l}\text { v. 3 } \\
\text { n. } 1\end{array}$ & p. 91-108 & 2010 - jan. / jun. & ISSN 1981-0601 \\
\hline
\end{tabular}

em que a natureza sociointeracional da linguagem não é colocada em primeiro plano, mesmo entre acadêmicos do curso de Letras em seus estágios de conclusão de curso, tem como base uma página do site da agência de turismo canadense Comfort Travel Inc., na qual são oferecidas duas opções de viagens pelo Canadá. O título, que se segue ao logotipo da empresa, é Explore Canada. Logo após, em destaque, são ofertados pacotes de viagem para as Cataratas do Niágara, e também uma excursão para as cidades de Montreal, Quebec e Ottawa, com partida de Toronto. Em seguida, são disponibilizados, de forma destacada, dois telefones para contato no caso de o visitante desejar mais opções de viagens. Depois disso, há um texto de três parágrafos descrevendo um pouco da história e geografia do Canadá e ofertando novamente a excursão para as três cidades canadenses. Finalmente, a última informação apresentada é uma lista de algumas das maiores cidades do Canadá, nas quais se incluem Montreal e Ottawa.

Dadas as particularidades desse texto, várias questões poderiam ser realizadas a fim de salientar seu propósito comunicativo, tais como: a intenção dos donos da agência de turismo ao colocarem o nome de Comfort Travel, especialmente levando em conta que são oferecidas viagens de ônibus, nem sempre relacionadas com conforto; os adjetivos utilizados para caracterizar os pacotes oferecidos; a natureza das informações disponibilizadas sobre história e geografia do Canadá, ou seja, se neutras ou tendenciosas; a motivação por acrescentarem uma lista com as maiores cidades do Canadá. Importante valorizar também, nesse contexto, questões sobre o porquê do destaque para os números de telefone e a função dos ícones "testimonials" e "photo gallery" que aparecem no lado esquerdo da página. Idealmente, o debate em torno dessas questões proporcionaria, além do entendimento da base linguística que compõe o texto, a compreensão da sua função, possibilitando, assim, uma maior familiaridade dos alunos com esse gênero.

Esse foco na função desempenhada pelo texto através do gênero a que este pertencia, entretanto, não pareceu estar entre as preocupações principais 


\begin{tabular}{|l|l|l|l|l|l|l|}
\hline InterteXto & Uberaba & UFTM & $\begin{array}{l}\text { v. 3 } \\
\text { n. } 1\end{array}$ & p. 91-108 & 2010 - jan. / jun. & ISSN 1981-0601 \\
\hline
\end{tabular}

do estagiário durante a elaboração da aula de leitura. Além de uma atividade específica de vocabulário - "Marque a opção abaixo que dê o melhor sentido para 'departure', no segundo ícone do panfleto" - foram acrescentadas três questões dissertativas e uma atividade de Verdadeiro ou Falso, com cinco afirmações.

As questões dissertativas se restringiam a aspectos bastante pontuais do texto, como identificação de informações relativas à melhor época para visitar as cataratas do Niágara e o local de onde as excursões iriam partir. 0 mesmo raciocínio vale para a atividade de Verdadeiro ou Falso, que focalizou o texto com informações relativas à história e geografia do Canadá. Nessas, somente o conhecimento da base textual foi valorizado, com os alunos devendo confrontar afirmativas como "os primeiros habitantes do Canadá foram os franceses" e "no passado, o Canadá pertenceu à França e Inglaterra" com as partes correspondentes no texto original - nesses casos, "The Aboriginals are the first people in Canada" e "In the past, Canada was owned by France and later England".

\section{Considerações Finais}

Como já afirmado por estudos anteriores e verificado aqui também, abordagens sociointeracionais para o ensino de língua materna e estrangeira, colocadas em relevo pelos PCNs a partir de 1988, ainda não constituem a base teórico-metodológica de todos os profissionais responsáveis pela educação linguística em nosso país. Essa situação já foi comprovada por outros estudos, mas, de modo geral, sempre partindo da realidade do professor já formado e com graus variados de experiência profissional. Nesse sentido, nosso artigo apresenta uma contribuição específica ao relacionar tal afirmação às práticas de ensino de professores em formação que, a princípio, teriam recebido base teórica suficiente ao longo do seu curso para chegarem aos estágios de conclusão habilitados a elaborarem propostas de atividades que refletissem uma visão sociointeracionista da linguagem - ou seja, de modo mais específico 


\begin{tabular}{|l|l|l|l|l|l|l|}
\hline InterteXto & Uberaba & UFTM & $\begin{array}{l}\text { v. 3 } \\
\text { n. } 1\end{array}$ & p. 91-108 & 2010 - jan. / jun. & ISSN 1981-0601 \\
\hline
\end{tabular}

ao que estivemos analisando ao longo deste artigo, habilitados a relacionar os textos utilizados em atividades de leitura à função por eles desempenhada.

Tal habilitação, a princípio, não nos parece um processo árduo. Conseguir relacionar o texto à sua função comunicativa, a partir do ensino de língua via gêneros, demanda a elaboração de questões que auxiliem os alunos a perceber os propósitos comunicativos dos textos, de propostas de comparações entre textos do mesmo gênero e também de gêneros diferentes, e outras possibilidades relativamente simples de serem realizadas.

O obstáculo maior, pelo menos na minha experiência, tem sido conseguir mostrar o que significa de fato ensinar língua estrangeira a partir de uma proposta sociointeracionista. Ainda que haja domínio dos conceitos relativos a essa abordagem, eles muitas vezes não se transformam em práticas de sala de aula. Já que descartamos aqui a hipótese de pouca exposição aos fundamentos teóricos das abordagens sociointeracionistas e de gêneros, penso que se deve considerar a possibilidade de que essa dificuldade de transposição didática tenha ocorrido, em parte, pela insuficiente exposição a essa abordagem nos momentos em que esses futuros professores estavam adquirindo, eles próprios, a língua estrangeira, seja na escola, seja em cursos de extensão, seja nas disciplinas da faculdade.

Partindo da máxima de que ensinamos o que aprendemos, esse pode muito bem ter sido o caso. Entretanto, não basta chegar a essa conclusão; é necessário, antes de mais nada, verificar se o que ensinamos está de acordo com o que de fato almejamos ensinar. Do mesmo modo, também é necessário verificar se o que almejamos ensinar pode ser acomodado nas condições reais de ensino. Atingir o ponto de equilíbrio entre esses dois parâmetros muitas vezes conflitantes - ideal de ensino e ensino possível - é o desafio de todo o professor. Para superá-lo, o primeiro passo, naturalmente, é dar-se conta de sua prática docente.

\section{Referências}




\begin{tabular}{|l|l|l|l|l|l|l|}
\hline InterteXto & Uberaba & UFTM & $\begin{array}{l}\text { v. 3 } \\
\text { n. } 1\end{array}$ & p. 91-108 & 2010 - jan. / jun. & ISSN 1981-0601 \\
\hline
\end{tabular}

ANTUNES, I. C. Língua, gêneros textuais e ensino: considerações teóricas e implicações pedagógicas. Florianópolis, Perspectiva, v. 20, n. 01, p. 65-76, jan./jun 2002.

BIASI-RODRIGUES, B. A diversidade de gêneros textuais nos livros didáticos: um novo modismo? Florianópolis, Perspectiva, v. 20, n. 01, p. 49-64, jan/jun. 2002.

BALDO, A. A percepção de gêneros textuais/discursivos pelo professor de língua materna. Curitiba, Letras, n. 67, p. 123-142, set./dez. 2005.

BAKHTIN, M. (1953) Os gêneros do discurso. In: Estética da Criação Verbal. São Paulo: Martins Fontes, 1997, p. 277-326.

BONINI, A. Ensino de gêneros textuais: a questão das escolhas teóricas e metodológicas. Trabalhos em Lingüística Aplicada, n. 37, p. 7-23, 2001.

BRASIL, SECRETARIA E MINISTÉRIO DE EDUCAÇÃO MÉDIA E TECNOLÓGICA. Parâmetros Curriculares Nacionais - Ensino Fundamental. Brasília, Ministério da Educação, 1998.

. Parâmetros Curriculares Nacionais - Ensino Médio. Brasília, Ministério da Educação, 1999.

BRONCKART, J. P. Atividade de Linguagem, Textos e Discursos: por um interacionismo sócio-discursivo. São Paulo: EDUC, 2003.

DOURADO, M. R. S. Dez anos de PCNs de Língua Estrangeira sem Avaliação dos Livros Didáticos pelo PNLD. Linguagem em (Dis)curso, vol. 8, n.1, 2008, p. 1-11.

EXPLORE CANADA. Disponível em http:Ilwww.comforttravel.ca/índex.php?func Page\&id=50. Acesso em 02/06/2010.

$\begin{array}{lllll}\text { ELLIS } & \text { PARK } & \text { STADIUM. } & \text { Disponível em }\end{array}$ htttp:IIfifa.com/worldcup/destination/ stadiums/stadium=5006468/índex.html, acesso em 02/06/2010. GERALDI, J. W. Portos de Passagem. São Paulo: Martins Fontes, 1991. MARCUSCHI, L. A. Produção Textual, Análise de Gêneros e Compreensão. 


\begin{tabular}{|l|l|l|l|l|l|l|}
\hline InterteXto & Uberaba & UFTM & $\begin{array}{l}\text { v. 3 } \\
\text { n. } 1\end{array}$ & p. 91-108 & 2010 - jan. / jun. & ISSN 1981-0601 \\
\hline
\end{tabular}

São Paulo: Parábola Editoral, 2008.

MEURER, J. L. O conhecimento de gêneros textuais e a formação do profissional da linguagem. In: Mailce Borges Mota Fortkamp e Lêda Maria Braga Tomitch (orgs). Aspectos da Lingüística Aplicada. Florianópolis: Insular, 2000.

MOITA LOPES, L. P. Um modelo interacional de leitura. In: Oficina de Linguística Aplicada. São Paulo: Mercado das Letras, 1996, p. 137-146. ORLANDI, E. P. Leitura, questão linguística, pedagógica ou social. In: Leitura e Discurso. São Paulo: Cortez, 1988, p. 35-40.

SCHNEUWLY, B.; DOLZ, J. Os gêneros escolares - das práticas de linguagem aos objetivos de ensino. Revista Brasileira de Educação, n. 11, Rio de Janeiro: ANPED, 1999. Tradução de Glaís Sales Cordeiro.

SCHNEWLY, B. et al. Gêneros Orais e Escritos na Escola. São Paulo: Parábola Editorial, 2004.

SILVA, M. C. Uso de gêneros textuais no ensino de leitura: da teoria aos modelos didáticos. Anais do III Simpósio Internacional de Gêneros Textuais. Tubarão: Editora da Unisul, 2007, p. 1-12.

THE BRAZILIAN PHANTASY PLACE. Disponível em http:Ilwww.vbrazil.com/tourism/fernandodenoronha.html. Acesso em 04/06/2010. 